\title{
CULTURA
}

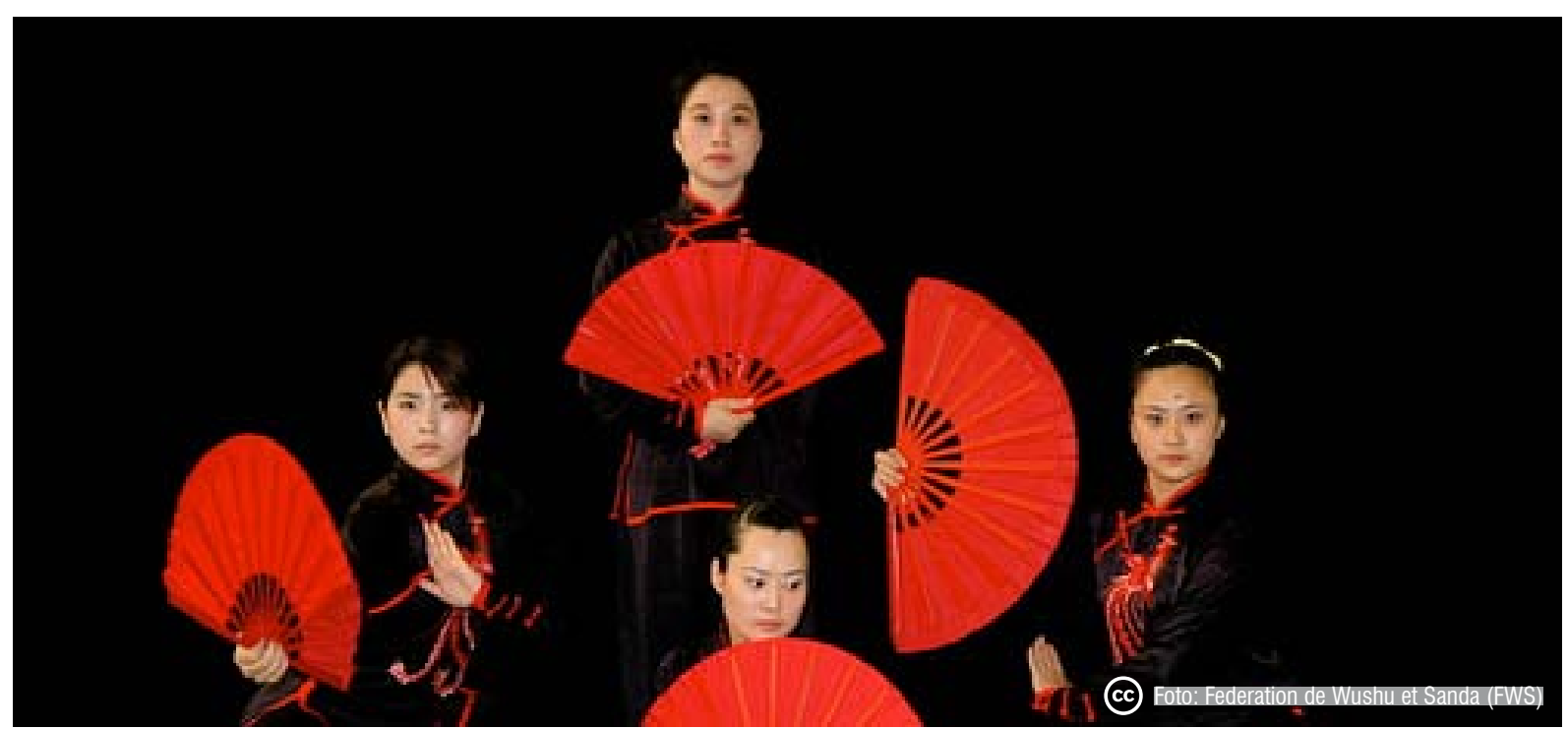

\section{WUSHU: \\ DE ARTE MARCIAL ORIENTAL A DEPORTE OCCIDENTAL}

$>>$

Laura Isabel Tenelanda Osorio

Estudiante de Ingeniería de

Procesos, Universidad EAFIT

E-mail: Itenelan@eafit.edu.co

\section{Resumen:}

En un principio el Wushu era considerado parte importante de la cultura y la filosofía china y aunque lo sigue siendo para muchos, ahora es más un deporte, con sus reglas e incluso federación mundial. En el artículo se describe brevemente su historia, lo que significaba para los chinos y lo que es ahora para el mundo. En este artículo se expone la opinión del autor acerca del cambio que ha tenido con respecto a sus inicios y porqué no debería ser así.

\section{Palabras clave:}

Wushu, Kung fu, deporte, artes marciales, cultura china. 


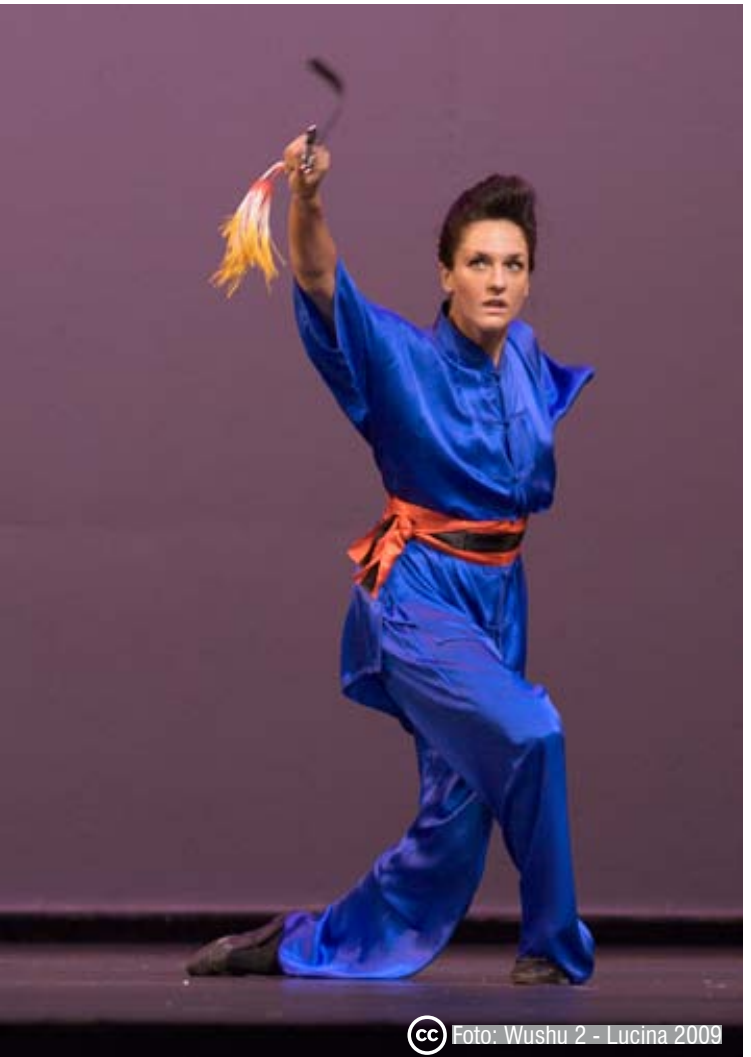

La palabra Wushu significa literalmente "Arte marcial" (Wu: marcial, Shu: arte). Consiste en una serie de movimientos semejantes a los de animales como la grulla, la serpiente, el tigre, entre otros, realizados en un principio para la conservación de la salud y la longevidad. Aunque Wushu es uno sólo, comúnmente se divide en dos ramas: interno (Tai Chi), en el que se usa la fuerza interna (neijia) para hacer movimientos lentos donde el Chi y la meditación juegan un papel fundamental; y el externo, que usa la fuerza externa (waijia) en la realización de movimientos rápidos y coordinados que requieren de fuerza y agilidad. Gracias a su expansión también suele llamarse Kung fu o Gong fu que significa esfuerzo o trabajo hecho con maestría, ya que se dice que el Wushu es un arte marcial hecha con maestría.

Su historia en oriente no está muy bien definida, unos dicen que comenzó en el templo Shaolin con los monjes taoístas y budistas, al llegar Ta-Mo (Bodhidarma), quienes lo practicaban para cultivar la mente y el cuerpo. Otros dicen que fue el pueblo chino el que comenzó con los movimientos para conservar la salud y así fue creando escuelas hasta hacerlo parte importante de su cultura. Incluso hay quienes dicen que es una herencia de al menos 400 años a.C cuando los antepasados lo usaban para supervivencia y defensa personal (Wushu Kung fu Perez Gongora, 2012).

Sin importar de dónde proviniera o quien lo hubiese inventado, la antigua población china consideraba firmemente que el principal objetivo de realizar este conjunto de movimientos era cultivar la energía tanto interna como externa, la meditación, conservar mente y cuerpo sanos, y no buscar herir a alguien o alcanzar reconocimiento alguno.

Sin embargo, en occidente está claro que, en la década de los ochenta, con la llegada de las películas de Bruce Lee y Jackie Chan, junto con escenas de combate, sangre y violencia, se expandieron algunas técnicas de Wushu. Y el problema no es que estas películas mostraran justo lo que el Wushu no es: (pelea), sino que estos giros, patadas, puños y saltos tuvieron una gran acogida y dejaron atrás lo más importante: su filosofía, y el significado cultural que este lleva consigo.

Lo que no se transmitía en las películas era su contenido interior y naturaleza, el verdadero objetivo de esta práctica, por lo que en occidente (e incluso los chinos jóvenes) se tiene una visión muy diferente de lo que éste es en realidad. En el Wushu no se busca dar puños y patadas porque sí, no se busca combatir, se pretende encontrar la felicidad, encontrarse con uno mismo, paz interior y evitar la pelea, por que como dice en el Tao Te King: "(...) Quien vence a los otros, es fuerte. Quien se vence a sí mismo, es poderoso (...)" (Lao, 2006).

Durante su historia "sobrevivió" a la prohibición de muchos emperadores chinos por miedo, y ahora se encuentra cerca a pasar de ser un arte marcial milenaria a ser simplemente un deporte, dejando atrás la cultura y filosofía tradicional.

Hay escuelas de Wushu donde se enseña sólo a golpear y pelear; hay profesores que enseñan y no maestros de los cuales aprender; se hacen torneos donde la pelea es el anfitrión y la algarabía y el espíritu de competencia son los invitados de honor. Y a pesar de que en el llamado Wushu moderno hay dos modalidades: Taolu (rutinas) y Sanda (combate), la más practicada es el Sanda. 


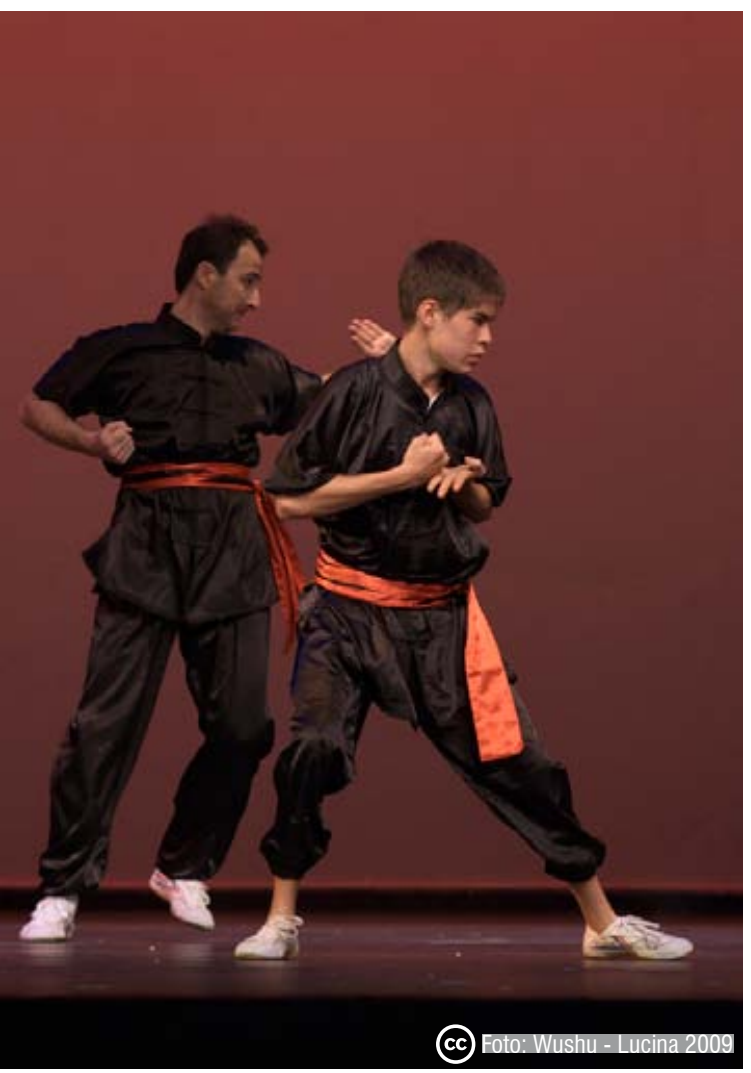

\section{Conclusiones}

Hoy en día el Wushu está bien organizado de manera tal que es el deporte nacional de China practicado por millones de personas en ese país. Incluso existe una federación de Wushu: International Wushu Federation (IWUF), la cual convoca los Campeonatos Mundiales de Wushu cada dos años.

En Colombia, por ejemplo, hay muchas ligas de Wushu en departamentos como Antioquia, Bogotá y Valle del cauca, entre otros, incluso hay una selección colombiana de Wushu, que representó al país en el quinto campeonato internacional de Taichí realizado en la ciudad de Wudang - China, (región considerada la cuna del Taichí en el mundo) y en la cual participan delegaciones de 28 países, obteniendo logros que se pueden catalogar como de carácter histórico (Coldeportes, 2012).

Realizar cualquier actividad física es beneficioso para la salud, para salir del estrés diario, y el Wushu no es la excepción ya que es en parte para eso, para buscar la tranquilidad de quien lo practica. Pero es totalmente diferente cuando este pasa a ser un deporte y aunque hay que reconocer que como tal es un éxito, el hecho de que el Wushu hubiese llegado a occidente debió aceptarse de manera diferente adaptándonos a él y no darle el giro que se le dio para que éste se adaptara a nuestra cultura.

\section{Referencias bibliográficas}

- Coldeportes. (2012). Recuperado el 25 de 10 de 2012, de Coldeportes: http://www.coldeportes.gov.co/ coldeportes/index.php?idcategoria $=50901$

- Lao, T. (2006). Tao Te Ching, Traducción. (I. P. Idoeta, Trad.) Madrid: Editorial Trotta.

- Wushu Kung fu Perez Gongora. (2012). ¿Qué es el Wushu? Recuperado el 10 de 2012, de Sitio Web del Instituto Wushu Kung fu Perez Gongora: http://www.wushupg.com/wushu.html

- Wushulonghuquan. (s.f.). Recuperado el 24 de 10 de 2012, de http://www.wushulonghuquan.com.ar/ que.htm 